\title{
Rekombinant ve Yabanıl Bakteriler ile Kromun Biyoremediasyonu*
}

\author{
Şeyma Akkurt ${ }^{1 \dagger}$, Merve Oğuz ${ }^{2}$ \\ 1 Adıyaman Üniversitesi Mühendislik Fakültesi, Çevre Mühendisliği Bölümü, Adıyaman (ORCID: 0000-0002-0135-1975) \\ ${ }^{2}$ Erciyes Üniversitesi Mühendislik Fakültesi, Çevre Mühendisliği Bölümü, Kayseri (ORCID: 0000-0002-8388-1477)
}

(Konferans Tarihi: 5-7 Mart 2020)

(DOI: $10.31590 /$ ejosat.araconf73)

ATIF/REFERENCE: Akkurt, Ş. \& Oğuz, M. (2020). Rekombinant ve Yabanıl Bakteriler ile Kromun Biyoremediasyonu. Avrupa Bilim ve Teknoloji Dergisi, (Özel Sayı), 604-609.

\section{$\ddot{O} \mathbf{z}$}

Günümüzde ağır metal kirliliği önemli çevre sorunlarından biri haline gelmiştir. Kadmiyum, kurşun ve krom gibi ağır metallerin düşük konsantrasyonları canlılar için toksiktir. Krom (Cr), dünyadaki en toksik ağır metallerden biridir ve endüstriyel olarak salınan yaygın bir çevresel kirleticilerdendir. Cr metal iyonu; biyolojik olarak parçalanmayan ve doğada biriken bir ağır metaldir. Krom, biyolojik olarak gerekli değildir ve alıcı ortamlara (su ve toprak gibi) yapılan deşarjlar sonucunda besin zinciri boyunca birikerek insanlara kadar aktarılır. Kromun ana kaynakları; tabakhaneler, elektrokaplama, madencilik, tekstil, metal işleme, gübre, boyalar ve pigment imalat sanayi gibi çeşitli endüstrilerdir. İnsan sağlı̆̆ ve su ekosistemleri üzerinde olumsuz etkileri olan krom metal iyonları, farklı arıtma teknolojileri ile su ve atık sudan uzaklaştırılmalıdır.

Krom giderimin de yaygın kullanılan metotlar; ters osmoz, elektrokimyasal prosesler, iyon değişimi, aktif karbona adsorpsiyon ve katılaştırma/stabilizasyondur. Bu yöntemlerin pahalı olmaları, yan ürün oluşumu ve çevre dostu olmamaları gibi bazı dezavantajları vardır. Biyoremediasyon prosesleri ise tüm bu sorunlara bir çözüm getirmiş ve çevre, ekonomi ve enerji açısından fayda sağlamıştır. Bakterilerin ağır metallere karşı geliştirdikleri direnç mekanizmaları sayesinde, ağır metallerin yüksek derişimlerinin olduğu ortamlarda hayatta kalırlar. Bakterilerin krom metal iyonunu bağlama kapasitelerini artırmak için biyoremediasyon umut verici bir prosestir. Yabanıl bakterilere, metalotiyonein, poli-histidinler veya poli-sisteinler gibi peptidler eksprese edilerek metal bağlama kapasitesini artırılabilmektedir. Bu derlemede; hücre içine metal girişinin engellenmesi, metalin proteinlere bağlanarak hücre içinde tutulması, metallerin hücrenin dışında tutulması, enzimlerle metalin daha az toksik forma dönüştürülmesi gibi direnç mekanizmalarına yer verilmiştir.

$\mathrm{Bu}$ çalışmada, bazı yabanıl ve rekombinant bakteri türlerinin krom metal iyonunu giderimleri araştırılmıştır. Bu derlemenin amacı kromu etkili bir şekilde bağlayan bakterileri ve proteinleri özetlemektir.

Anahtar Kelimeler: Ağır metal, biyoremediasyon, krom.

\section{Bioremediation of Chromium with Recombinant and Wild Bacteria}

\begin{abstract}
Today, heavy metal pollution has become one of the most important environmental problems. Low concentrations of heavy metals such as cadmium, lead and chromium are toxic to living things. Chromium (Cr) is one of the most toxic heavy metals in the world and is a common industrially released environmental pollutant. Chromium is a heavy metal that is non-biodegradable and accumulated in nature. For this reason, it is very important to treat chromium metal ion by making it suitable for discharge limits. Chromium is not
\end{abstract}

\footnotetext{
* Bu makale International Conference on Access to Recent Advances in Engineering and Digitalization (ARACONF 2020) de sunulmuştur.
} 
biologically necessary and accumulates along the food chain as a result of discharges to receiving environments (such as water and soil) and transferred to humans. The main sources of chromium are various industries such as tanneries, electroplating, mining, textile, metal processing, fertilizer, dyes and pigment manufacturing industry. Chromium metal ions, which has negative effects on human health and water ecosystems, should be removed from water and wastewater with different treatment technologies.

The most widely used methods are for chromium removal conventional physicochemical processes such as reverse osmosis, electrochemical process, ion exchange, adsorption on activated carbon, and solidification/stabilization, etc. These disadvantages, such as being expensive, waste product formation and being not environmentally friendly, limit their use. Bioremediation processes have brought a solution to all these problems and have benefited in terms of environment, economy and energy. Thanks to the resistance mechanisms developed by bacterias against heavy metals, they survive in environments with high concentrations of heavy metals. Bioremediation is a promising process to increase the capacity of bacteria to bind chromium metal ion. In this review; Resistance mechanisms such as preventing the entry of metal into the cell, keeping the metal in the cell by binding to proteins, keeping the metals out of the cell, and turning the metal into less toxic form with enzymes are included.

In this study, the efficiencies of some wild and recombinant bacterial species on the removal of chromium will be investigated. The purpose of this review is to summarize bacteria and proteins that bind chromium metal ions effectively.

Keywords: Heavy metal, bioremediation, chromium.

\section{Giriş}

Günümüzde sanayileşmenin artmasıyla birlikte krom, kadmiyum, bakır, kurşun gibi toksik metalllerin doğaya salınımı da artış göstermektedir. $\mathrm{Bu}$ ağır metalleri içeren atıksular alıcı ortamlara (su, toprak ve hava) deşarj edilmektedir. Ağır metallerin doğada parçalanamaması nedeniyle bulunduğu ortamda birikmektedir. Besin zinciri ile insanlara kadar aktarılmaktadır. Bu birikim sonucunda canlı sistemlerde olumsuz etkilere neden olmaktadır. Bitkilerde düşük büyüme oranlarına, insanlarda kansere ve ölüme kadar önemli sağlık problemlerine neden olmaktadır (Fernandez ve ark., 2018). Krom genellikle; elektrokaplama, ahşap koruma, deri, madencilik endüstrileri ve diğer endüstriyel faaliyetler gibi çeşitli kirletici kaynaklardan toprağa ve suya deşarj edilmektedir (Tekerlekopoulou ve ark., 2013).

Kromatın, suda kolay bir şekilde çözündüğü hem prokaryotlar hem de ökaryotlar için toksik olduğu bilinmektedir (Parker ve ark., 2011). Bu nedenle su ve topraktaki krom konsantrasyonu oldukça önemlidir. Bu ağır metal birçok ülkede ve Amerika Birleşik Devletleri Çevre Koruma Ajansı (USEPA) tarafından öncelikli kirleticiler listesine alınmıştır. USEPA'ya göre, yüzey suyu içerisindeki toplam Cr için izin verilen maksimum tolerans sinırı $0.5 \mathrm{mg} / \mathrm{L}$ 'dir [Tekerlekopoulou ve ark., 2013, Baral ve Engelken, 2002). Dünya Sağlık Örgütü (WHO) tarafından içme suyunda izin verilen toplam krom sınır değeri ise $0.05 \mathrm{mg} / \mathrm{L}$ olarak belirlenmiştir (Kumar ve Dwivedi, 2019).

Bu yüzden kromun çevreye zarar vermeyen etkili arıtma yöntemleri ile arıtılması gereklidir (Witek-Krowiak, 2013). Krom içeren atıksuların arıtımında; adsorbsiyon, ters ozmoz, iyon değişimi, kimyasal çökelme, membran teknolojileri, elektrokimyasal prosesler gibi fizikokimyasal yöntemler bulunmakla birlikte gerek arıtım süreçlerinin zorluklar içermesi arıtma veriminin düşük olması, zararlı atık ürün oluşumu, proseslerin komplike olması ve pahalı olmaları nedeniyle endüstriyel uygulamalarda çok fazla kullanılmamaktadır (Wong ve Kwok, 1992).

Kromun endüstriyel atıksulardan giderimi için ekonomik, çevre dostu, ucuz, güvenli ve etkili arıtma teknolojileri kullanılmalıdır (Fernandez ve ark., 2018). Biyoremediasyon istenilen bu özelliklerin tamamını taşımaktadır. Proseste, doğada bulunan mikroorganizmalar kullanılarak kirletici maddeler biyolojik olarak parçalanır ve çevreye zarar vermeyecek formlara dönüştürülür (Çınar Acar, 2018). Alt başılıklarda konu ile ilgili detaylı bilgi verilecektir.

\section{Kromun Özellikleri}

Krom; arsenik, civa, kurşun, kadmiyum, nikel, demir, bakır, çinko gibi ağır metaller canlıların hayatını olumsuz yönde etkileyen ve çevreye zarar veren birçok alanda yaygın olarak kullanılan kirleticilerdir (Taran ve ark., 2015).

Krom, dünyada yaygın olarak bulunan yedinci element olup, atom numarası 24, atomik ağırlığı 51,996 gr/mol olan toksik bir elementtir (Evgen, 2012). Krom; kayaçlarda, mineral topraklarında ve tatlı suda yaygın olarak bulunan bir jeokimyasal elementtir (Fernandez ve ark., 2018).

Doğada, Cr'nin birkaç farklı formu vardır ancak kararlı formları altı değerli Cr (VI) ve üç değerli Cr (III) türleridir (Su ve ark., 2018). Kromun oksijen ile reaksiyonu sonunda kromat $\left(\mathrm{CrO}_{4}^{-2}\right)$ veya dikromat $\left(\mathrm{Cr}_{2} \mathrm{O}_{7}^{-2}\right)$ iyonu şekline dönüşerek doğada bu şekilde bulunur. Kromat (Cr(VI)) ortamdaki organik madde ile reaksiyona girerek $\mathrm{Cr}$ (III)'e indirgenmesi sonucunda daha az toksik hale gelir (Kahvecioglu ve ark., 2003).

Cr (VI) canlı hücreler için esansiyel olmayan bir metaldir ve Cr (III)'e göre canlılar için 100 kat daha toksiktir. Bu nedenle kromun indirgenerek çevre için daha az zararlı forma dönüştürülmesinde veya tamamen giderilmesinde biyoremediasyonun rolü oldukça önemlidir (Su ve ark., 2018).

\section{Biyoremediasyon Prosesi}

Biyolojik arıtımda mikroorganizmaların kullanılması arıtımın daha etkili ve randımanlı yapılmasını sağlamaktadır. Ancak mikroorganizmaların ağır metalleri giderimi iki aşamadan oluşmaktadır. Biyolojik olarak ağır metallerin gideriminde, ilk olarak mikroorganizmaların hücre duvarında ağır metaller adsorbe edilmektedir. Bu olay hızlı bir şekilde gerçekleşir. Hücre yüzeyinde 
tutulma; polisakkaritler, proteinler ve lipidler gibi hücre duvarı bileşenlerinde bulunan fonksiyonel gruplar tarafindan gerçekleştirilmektedir. Fonksiyonel gruplar metalleri bağlamada farklı affinitelere sahip olan amino, karboksilik, sülfidril, fosfat ve thiol gruplarıdır. Bazı mikroorganizmaların hücre yüzeyinde polifosfatlara benzeyen moleküller ile metallerle kompleks oluştururlar (Ting ve ark., 1991; Volesky ve Holan, 1993).

Metallerin hücre yüzeyinde pasif olarak tutulmasına biyosorpsiyon denir (Shumate ve Strandberg, 1985). Biyosorpsiyon hem canlı hem de ölü biyokütlelerde gerçekleşmektedir (Şencan, 2006). İkinci aşamada ise ağır metallerin hücre içine alımı oldukça yavaştır ve hücre membranının transport özelliğine bağlı olarak sitoplazmaya geçmektedir. Metaller sitoplazmada mikradepositler şeklinde çözünmez formda tutulmaktadır (Volesky ve Holan, 1993).

Metallerin hücre içinde birikimi, mikroorganizmalar canlı oldukları zaman gerçekleşmektedir. Canlı hücreler ağır metalleri hücre içinde ve hücre dışında biriktirme özelliğine sahiptir. Bu olay biyoakümülasyon olarak adlandırılır. Biyoakümülasyon prosesinde metallerin aktif ve pasif olarak tutulur (Shumate ve Strandberg, 1985).

Ayrıca biyoremediasyon prosesi, mikroorganizmaların ağır metalleri hücre içine alarak zararlı etkilerininin azaltılıp daha az zararlı hale dönüştürülmesi olarakta adlandırılmaktadır ((Witek-Krowiak, 2013; Çınar Acar, 2018).

Biyoremediasyon, metallere karşı dirençli ve metalleri gideren mikroorganizmaların kirliliğin olduğu çevreye salınmasıyla yapılabilir. Eğer biyoremediasyon prosesinde kullanılacak mikroorganizma, arıtılmak istenilen metal üzerinde etkili değilse, doğaya salındıktan sonra metal hızlı bir şekilde populasyonu öldürecektir. Sonuç olarak etkili bir arıtım yapılmamış olacaktır. Bu durumun önüne geçebilmek için asit ile muamele edilmiş, yüksek dirence sahip ve giderim kapasitesi yüksek mikroorganizmaların kullanılması ile sağlanabilir (Ergül Ülger, 2016).

Mikroorganizmalar ağır metallere karşı geliştirdikleri direnç mekanizmaları sayesinde, ağır metallerin yüksek derişimlerinin olduğu ortamlarda hayatta kalırlar. Bakterilerin geliştirdikleri bu mekanizmalar aşağıda sıralanmıştır (Koçberber Kılıç, 2008).

\section{Hücre içine alınmama}

II. Metalin proteinlere baglanması ile hücre içinde tutulması

III. Metalin daha az toksik forma dönüstürülmesi

IV. Metalin mikroorganizmadan aktif olarak tasınması

V. Metalin hücre disında tutulması

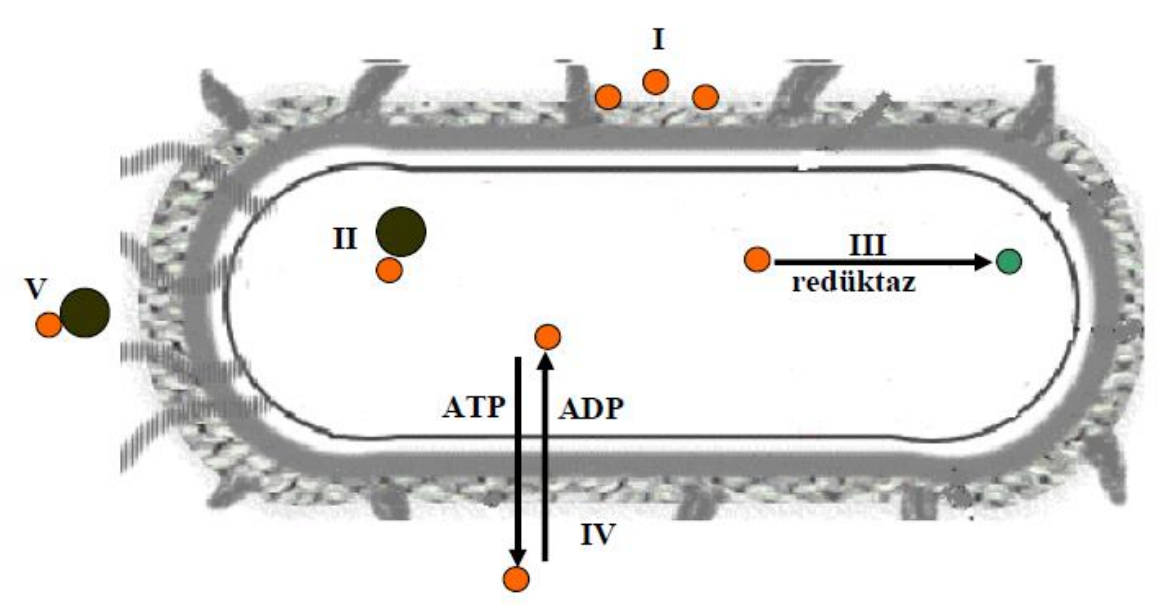

Şekil 1. Mikroorganizmalarda bulunan metal direnç sistemlerinin sematik gösterimi

\section{- Hücre İçine Metal Girişinin Engellenmesi:}

Metalin, hücre zarından içeri girmesi mikroorganizmaların hücre duvarında, hücre zarında veya dış zar proteinlerinde bazı değişiklikler olması ile engellenir. Aslında burda amaç esansiyel hücre bileşenlerinin korumanmasıdır. Ekstrasellüler polisakkaritler metal iyonlarını biyolojik olarak bağlar ve hücrenin korunması sağlanır (Koçberber Kılıç, 2008).

E. coli'deki zar kanal proteini porini değiştirerek Cu(II)'nin içeri alınmaması bu mekanizmaya örnek verilebilir. Bu durum, mutasyon sayesinde metal iyonlarına karşı zarın geçirgenliğinin azaltılması olup tek gen mutasyonu ile açıklanmaktadır (Bruins ve ark., 2000).

\section{- Metalin proteinlere bağlanarak hücre içinde tutulması:}

$\mathrm{Bu}$ mekanizmada ise ağır metallerin hücre içinde vakuollerde veya sitoplazmada biriktirilerek hücre metabolizmasını ve hücre bileşenlerini etkilemesi engellenmektedir (Koçberber Kılıç, 2008; Bruins ve ark., 2000). 
- Metalin proteinlere bağlanarak hücre içinde tutulması:

Bu mekanizmaya Synehococcus sp.'deki metallotiyonein ve Pseudomonas sp.'nin sisteince zengin proteinlere bağlanması örnek olarak verilebilir (Koçberber Kılıç, 2008).

\section{- Metallerin mikroorganizmadan aktif olarak uzaklaştırılması:}

Mikroorganizmalar metalleri sitoplazmalarının dışına aktif taşıma ile pompalayarak atarlar. Bu mekanizma ATP'ye bağımlı ya da ATP'den bağımsız olarak gerçekleşebilir. Etkili olan genler plazmid kökenli veya kromozom kökenlidir.

$\mathrm{Bu}$ direnç sistemine örnek olarak; Bacillus sp.'de civa direnci ve arseniğin P tipi ATPazlarla dişarı pompalanması, E.coli'de arsenigi dışarı pompalayan kromozom üzerinde bulunan genler bu direnç sistemlerine örnek oluşturmaktadır (Silver, 1996; Rosen, 2002).

\section{- Hücrenin dışında metallerin tutulması:}

Bu mekanizma, bakterilerde, mayalarda ve funguslarda görülmüştür. Bu mekanizma, Saccharomyces cerevisiae yüksek miktarda glutatyon salgılamış ve Ni(II)’in bu komplekse bağlanarak hücreye girmesi engellenmiştir (Ergül Ülger, 2016; Koçberber Kılıç, 2008).

\section{- Enzimlerle metalin daha az toksik forma dönüştürülmesi:}

Bu mekanizma gram negatif ve gram pozitiflerde bakterilerde olup enzimatik olarak veya hücre içinde dönüştürülür. Daha önce yapılmış olan çalışmalarda $\left(\mathrm{AsO}_{4}\right)^{-3}, \mathrm{Hg}(\mathrm{II})$ ve $\mathrm{Cu}(\mathrm{II})$ gibi metaller daha az toksik forma dönüştürülmüştür (Koçberber Kılıç, 2008).

Ayrıca birçok mikroorganizma ağır metallerin olduğu ortamlarda kendini korumak için metal bağlayıcı proteinler sentezlediği yapılmış çalışmalarda görülmüş̧ür. Hatta artan metal konsantrasyonu ile doğru orantılı olarak metal bağlayıcı protein sentezinin de arttığı da görülmüştür (Gadd, 1990; Han, 1992).

\section{Bakteriler İle $\operatorname{Cr}($ VI) Birikimi ve Biyogiderim Çalışmaları}

Birçok mikroorganizmanın yüksek oranda çözünür ve toksik Cr (VI)'yı daha az çözünür ve daha az toksik Cr (III)'e indirgenmesi üzerine birçok çalışma yapılmıştır. Örneğin; Acinetobacter ve Ochrobactrum (Francisco ve ark., 2002), Arthrobacter (Megharaj ve ark., 2003), Pseudomonas sp. (Rajkumar ve ark., 2005), Serratia marcescens (Campos ve ark., 2005), Ochrobactrum sp. (Thacker ve Madamwar, 2005), Bacillus sp. (Elangovan ve diğerleri, 2006), Desulfovibrio vulgaris (Goulhen ve diğerleri, 2006), Cellulomonas spp. (Viamajala ve ark., 2007) bu çalışmalardan bazılarıdır. Yapılan çalışmalar aşağıda detaylı olarak verilmiştir.

Velasquez ve Dussan (2009) tarafından yapılan çalışmada, civa, bakır, demir ve krom elementlerine karşı Kolombiya'da elde edilen farklı Bacillus sphaericus suşlarının toleranslarını ve biyogiderimlerini araştırmışlardır. Suşun krom elementinin gideriminde canlı hücrede \% 25 oranında etkili iken ölü hücrede \% 44,5’lik oranda etkili olduğunu bildirmişlerdir (Velásquez ve Dussan, 2009).

Başka bir çalışmada, bir atıksu arıtma tesisinin atıksuyundan izole edilen suşların $\mathrm{Cr}$ (VI) gideriminde olan etkinliği araştırılmıştır. İzole edilen suşlar arasında Bacillus circulans ve Bacillus megaterium olduğu tespit edilmiş ve bakterilerin kuru ağırlıkları; 34,5 mg Cr/g ve $32 \mathrm{mg} \mathrm{Cr} / \mathrm{g}$ olduğu belirlenmiştir. Ayrıca çalışmada krom gideriminde ölü hücrelerin canlı hücrelere göre daha etkili olduğu saptanmıştır (Srinath ve ark., 2002).

Bir diğer çalışmada ise, deri sanayi atıklarından bir Bacillus suşunun krom giderme yeteneği araştırılmıştır. İzole edilen bakterinin, 800 ppm Cr (VI)'ya kadar dirençli olduğu ve 72 saat içerisinde \% 41,8 kromu giderdiği ileri sürülmüştür (Singh ve Malaviya, 2015).

Sathishkumar ve arkadaşlarının (2017) yapmış olduğu çalışmada Pseudomonas stutzeri L1 ve Acinetobacter baumannii L2 suşlarının Cr(VI) giderme kabiliyetleri incelenmiştir. Çalışmada farklı pH, sıcaklık ve başlangıç Cr (VI) dozunun gibi parametrelerin $\mathrm{Cr}(\mathrm{VI})$ indirgenmesi üzerine etkisi araştırılmıştır. $100 \mathrm{mg} / \mathrm{L} \mathrm{Cr}$ (VI)’u 24 saatlik inkübasyonun sonunda, P. stutzeri L1 suşunun \% 97 ve A. baumannii L2 suşunun \% 99 oranlarında indirgediği sonucuna varılmıştır (Sathishkumar ve ark., 2017).

Robins ve arkadaşları (2013) tarafindan yapılan çalışmada, polihidroksialkanoat granülleri üzerinde hareketsizleştirilmiş stabil ve aktif bir kromat redüktazına dayanan bir sistem geliştirmek için $R$. eutropha'dan alınan nemA ve polihidroksialkanoat sentaz genleri E. coli'ye füzyonlanmıştır. Böylece, yabanıl türe göre 200 kat daha fazla kromat indirgeyen ChrR6 adı verilen bir mutant enzimi aşırı eksprese edilen bir mikroorganizma elde edilmiştir (Robins ve ark., 2013).

Ackerley vd. (2004) tarafindan yapılan bir çalışmada Pseudomonas putida bakterisinden ChrR ve E. coli bakterisinden YieF proteinlerinin kromat redüktaz aktivitesine sahip olup olmadıkları araştırılmış ve sonuç olarak bu iki genin kromun indirgenmesinde etkili olduğu sonucuna varılmıştır (Ergül Ülger, 2016). Genetik mühedisliği uygulamaları kullanılarak rekombinant mikroorganizmalarla bazı çalışmalarda yapılmıştır.

Özbey ve Asma (2019) tarafından yapılan çalışmada Cr'un yabanıl Deinococcus radiodurans ile Vitreoscilla hemoglobin (vgb) geni klonlanmış rekombinantının üremesi üzerine olan etkisi araştırılmıştır. Kullanılan Cr dozları; 250 ppm, 500 ppm, 1000 ppm, 1500 ppm ve 2000 ppm dir. Rekombinant suşun 1500 ppm'lik Cr uygulanmış vgb geni sayesinde üremeye devam ettiği görülmüştür (Özbey ve Asma, 2019). 
Kılıç ve Dönmez (2008) tarafindan yapılan çalışmada, Pseudomonas aeruginosa, Micrococcus sp. ve Ochrobactrum sp. Mikroorganizmalarının değişen $\mathrm{pH}$, sıcaklık, Cr (VI) konsantrasyonu ve inkübasyon sürelerindeki hücredışı polisakkarid üretimlerindeki değişim araştırılmıştır. Mikroorganizmalar arasında Pseudomonas aeruginosa suşunda en yüksek polisakkarid üretimi olduğu saptanmıştır.

Zahoor ve Rehman (2009)'ın yaptıkları çalışmada, Bacillus sp. JDM-2-1 ve Staphylococcus capitis suşlarının hekazavalent Cr (VI)'yı daha az toksik formu olan Cr (III)'e indirgeyebilme kapasiteleri incelenmiştir. Bakterilerin Cr (VI)'ya dayanma kapasiteleri sırasıyla; Bacillus sp. JDM-2-1' in $4800 \mu \mathrm{g} / \mathrm{mL}$ 'ye ve S. capitis' in $2800 \mu \mathrm{g} / \mathrm{mL}$ olduğunu göstermiş̧tir.

Polti ve arkadaşları tarafından (2010) daha önce yapılan çalışmalarında Streptomyces sp. MC1'in sentetik ortamda ve toprak örneklerinde bulunan $\mathrm{Cr}$ (VI)'yı daha az toksik formu olan $\mathrm{Cr}$ (III)'e indirgeyebildiğini bildirmişlerdir. Bu çalışmada ise optimal pH, sıcaklık, büyüme evresi ve elektron kaynaklarının Cr (VI)'nın in vitro koşullarda indirgenmesi üzerine çalışmışlardır. $\mathrm{Cr}(\mathrm{VI})$ indirgenmesinde optimum şartlarının $30^{\circ} \mathrm{C}$ ve $\mathrm{pH} 7$ 'de kromat reduktaz enzimi ile yapıldığını ifade etmişlerdir.

Caravelli ve arkadaşları tarafindan (2008) aktif çamur arıtma sistemlerinde bulunan Sphaerotilus natans bakterisinin Cr (VI)'y1 indirgeyebilme kapasitesi incelenmiş̧ir. Bakterinin aerobik şartlarda $80 \mathrm{mg} / \mathrm{L}$ 'ye kadar Cr (VI) ve Cr (III)'ü yüksek verimde indirgediği saptanmıştır.

$\mathrm{Bu}$ ve buna benzer teknikler geliştirmek için araştırmalara devam edilmelidir. Kromun etkili bir şekilde giderimi için bu çalışmalar umut vaad etmektedir.

\section{Sonuç}

Metallerin biyolojik prosesler ile giderimi ve geri kazanımı, kullanılan geleneksel fizikokimyasal arıtım yöntemlerine önemli bir alternatiftir. Özellikle kirlenmiş ortamlardan izole edilen bakteri türleri krom ve diğer ağır metallere karşı geliştirdikleri doğal direnç mekanizmaları sayesinde yüksek metal konsantrasyonlarına dayanabilmektedir. Bakterilerin krom bağlama kapasitelerini arttırmak için etkili olduğu düşünülen genler plazmidler aracılığıyla istenilenen hücreye aktarılarak rekombinant türler geliştirilmektedir.

Rekombinant DNA teknolojisi kullanılarak istenilen bir gen bakterilere aktarılarak bir bakteri türü ile aynı anda birden fazla metal giderilebilir. Bunun için daha fazla çalışmalar yapılmalı, yeni genler ve bakteriler araştırılmalıdır. Bu şekilde ağır metallerin giderimi ya da geri kazanımı daha etkili bir şekilde yapılabilir. Pilot ölçekli çalışmalarda gen ve bakterilerin etkinliği tespit edilerek, endüstriyel atıksuların arıtımında kullanımı yaygın hale getirilebilir. Endüstriyel atıksulardan metal arıtımında kullanılacak reaktörler bu bakterilerin doğaya salınmasını önleyecek şekilde tasarlanmalıdır. Çünkü rekombinant bakteriler doğaya salındığında ortamı istila ederek diğer canlıları yok olmasına yol açabilirler. Ağır metallerin giderimi üzerinde rekombinant bakteriler ile daha fazla çalışmalar yapılarak büyük ölçekte kullanımı yaygın hale getirilebilir.

\section{Kaynakça}

Fernandez, P.M., Vinarta, S.C., Bernal, A.R., Cruz, E. L., Figueroa. L.I.C. (2018). Bioremediation strategies for chromium removal: Current research, scale-up approach and future perspectives. Chemosphere, Vol. 208, 139-148.

Tekerlekopoulou, A.G., Tsiflikiotou, M., Akritidou, L. Viennas, A., Tsiamis, G., Pavlou, S., Bourtzis, K., Vayenas. D.V. (2013). Modelling of biological $\mathrm{Cr}(\mathrm{VI})$ removal in draw-fill reactors using microorganisms in suspended and attached growth systems. Water Research, vol. 47, 623-636.

Parker, D.L., Borer, P., Bernier-Latmani., R. (2011). The response of Shewanella oneidensis MR-1 to Cr(III) toxicity differs from that to $\mathrm{Cr}(\mathrm{VI})$. Frontiers in Microbiology, vol. 2, 1-14.

Baral, A., Engelken, R.D. (2002). Chromium-based regulations and greening in metal finishing industries in the USA. Environmental Science \& Policy, vol. 5, 121-133.

Kumar, V., Dwivedi, S.K. (2019). Hexavalent chromium reduction ability and bioremediation potential of Aspergillus flavus CR500 isolated from electroplating wastewater. Chemosphere, vol. 237, 1-11.

Witek-Krowiak, A. (2013). Kinetics and equilibrium of copper and chromium ions removal from aqueous solutions using sawdust. Environmental Engineering and Management Journal, vol. 12, 2125-2135.

Wong, P.K., S.c. Kwok. (1992). Accumulation of nickel ion $\left(\mathrm{Ni}^{+2}\right)$ by imı11obilized ceIls of Enterobacter species. Biotechnol Letters, 14:7,629-634 p.

Çınar Acar, B. (2018). Doktora Tezi. Endüstriyel Atıksulardan Biyoremediasyon İle Kromun Detoksifikasyonu, Doğal ve Kimyasa/Biyolojik Yöntemlerle Modifiye Edimiş Kil Üzerine Krom Adsorpsiyonunun Merkezi Kompozit Tasarım Yöntemi Kullanılarak İncelenmesi. Gazi Üniversitesi, Fen Bilimleri Enstitüsü, Ankara.

Taran, M., Sisakhtnezhad, S., Azin, T. (2015). Biological removal of nickel (II) by Bacillus sp. KL1 in different conditions: optimization by Taguchi statistical approach. Polish Journal of Chemical Technology, vol.17(3), 29-32.

Evgen, E. (2012). Yüksek Lisans Tezi. Pseudomonas Cinsi Bakterilerde Hekzavalent Krom İndirgeme Üzerine Ağır Metallerin Etkisi. Pamukkale Üniversitesi Fen Bilimleri Enstitüsü, Denizli.

Su, Y. Q., Zhao, Y. J., Wu, N., Chen, Y. E., Zhang, W. J., Cao, D. R. Q, Y. (2018). Chromium removal from solution by five photosynthetic bacteria isolates. Applied Microbiology and Biotechnology, vol. 102, 1983-1995.

Kahvecioglu, Ö., Kartal, G., Güven, A., Timur, S. (2003). Metallerin Çevresel Etkileri. İTÜ Metalurji ve Malzeme Mühendisligi Bölümü. İstanbul.

Ting, Y. P., Lawson, F. Prince, L. G. (1991). Uptake of cadmium and zinc by the alga Chlorella vulgaris: II Multi-ion stiation. Biotechnology Bioengineering, vol.37, 445-455. 
HoIan, Z. R., Volesky, B., Prasetyo, I. (1993). Biosorption of cadmium by biomass of marine algae. Biotechnology and Bioengineering, vol. 41, 819-825.

Shumate, S. E., Strandberg, G.W. (1985). Accumulation of Metals By Microbial Cell. In Compherensive Biotechnology, 4, $235-240$.

Şencan, A. (2006). Yüksek Lisans Tezi. Sulu Çözelti ve Deri Endüstrisi Atıksuyundan Cr(VI) İyonunun Aktif Çamur Biyokütlesi ile Biyosorpsiyonu. Süleyman Demirel Üniversitesi. Fen Bilimleri Enstitüsü, Isparta.

Volesky, B., May, R., Holan, Z. R. (1993). Cadmium biosorption by Saccharomyces cerevisiae. Biotechnology Bioengineering, vol. 41, 826-289.

Ergül Ülger, Z. (2016). Ağır Metal İçeren Atıksulardan İzole Edilecek Bakteriler İle Cr(VI) Biyoremediasyonu,” Doktora Tezi, Ankara Üniversitesi, Fen Bilimleri Enstitüsü, Ankara,

Koçberber Kılıç, N. (2008). Doktora Tezi. Proteomik Yaklaşımla Atıksu Kaynaklı Mikroorganizmalarda Cr(VI) Direnç Yollarının Araştırılması. Ankara Üniversitesi, Fen Bilimleri Enstitüsü, Ankara.

Bruins, M. R., Kapil, S., Oehme, F. W. (2000). Microbial resistance to metals in the environment. Ecotoxicology and Enviromental Safety, vol. 45, 198-207.

Silver, S. (1996). Bacterial resistance to toxic metal-ions-a review. Gene, vol. 179, 9-19.

Rosen, B. P. (2002). Transport and detoxification systems for transition metals, heavy metals and metalloids in eukaryotic and prokaryotic microbes. Comparative Biochemistry and Physiology, Part A vol. 133, 689-693.

Gadd, G. M. (1990). Biosorption," Journal Of Chemistry And Industry. 421-426.

Han, N. S., Seo, J. R., Chung, Y.C. (1992). Growth and copper resistance of recombinant Saccharomyces cerevisiae containing a metallothionein gene. Biotechnology Letters, vol. 14, no:1, 7-11.

Francisco, R,. Alpoim, M. C., Morais, P. V., (2002). Diversity of chromium-resistant and reducing bacteria in a chromium contaminated activated sludge. Journal of Applied Microbiology, 92: 837-843.

Megharaj, M., Avudainayagam, S., Naidu, R., (2003). Toxicity of hexavalent chromium and its reduction by bacteria isolated

from soil contaminated with tannery waste. Current Microbiology, 47: 51-54.

Rajkumar, M., Nagendran, R., Lee, K. J., Lee, W. H. (2005). Characterization of a novel Cr(VI) reducing Pseudomonas sp. with plant growth-promoting potential. Current Microbiology, 50: 266-271.

Campos, V. L., Moraga, R., Yanez, J., Zaror, C. A., Mondaca, M. A., (2005). Chromate reduction by Serratia marcescens isolated

from tannery effluent. Bulletin of Environmental Contamination and Toxicology, 75: 400-406.

Thacker, U., Madamwar, D. (2005). Reduction of toxic chromium and partial localization of chromium reductase activity in bacterial isolate DM1. World Journal of Microbiology and Biotechnology, 21: 891-899.

Elangovan, R., Abhipsa, S., Rohit, B., Ligy, P., Chandraraj, K., (2006). Reduction of Cr(VI) by a Bacillus sp. Biotechnology Letter, 28: 247-252.

Goulhen, F., Gloter, A., Guyot, F., Bruschi, A., (2006). Cr(VI) detoxification by Desulfovibrio vulgaris strain Hildenborough: microbe-metal interactions studies. Applied Microbiology and Biotechnology, 71: 892-897.

Viamajala, S., Smith, W. A., Sani, R. K., Apel, W. A., Petersen, J. N., Neal, A. L. (2007). Isolation and characterization of Cr(VI) reducing Cellulomonas spp. from subsurface soils: Implications for long-term chromate reduction. Bioresource Technology, 98: 612-622.

Velásquez, L., Dussan, J. (2009). Biosorption and bioaccumulation of heavy metals on dead and living biomass of Bacillus sphaericus. Journal of Hazardous Materials, vol. 167, 713-716.

Srinath, T., Verma, T., Ramteke, P.W., Garg, S.K. (2002). Chromium (VI) biosorption and bioaccumulation by chromate resistant bacteria. Chemosphere, vol. 48, 427-435.

Singh, A., Malaviya, P. (2015). Optimization of culture parameters for tannery effluent bioremediation by Bacillus galactosidilyticus APBS5-3," Journal of Environmental Biology, Vol. 36, no: 5, 1149-1152.

Sathishkumar, K., Murugan, K., Benelli, G., Higuchi, A., Rajasekar, A.(2017). Bioreduction of hexavalent chromium by Pseudomonas stutzeri L1 and Acinetobacter baumannii L2. Annals of Microbiology, vol. 67, 91-98.

Robins, K.J., Hooks, D.O., Rehm, B. H. A., Ackerley, D. F. (2013). Escherichia coli NemA is an efficient chromate reductase that can be biologically immobilized to provide a cell free system for remediation of hexavalent chromium. PLoS One, vol. 8, 1-8.

Özbey, E., Asma, D. (2019). Krom'un Deinococcus radiodurans ve Rekombinantlarına Etkisi. Iğdır Üniversitesi Fen Bilimleri Enstitüsü Dergisi, vol. 9, no: 3, 1305-1315.

Kiliç, N.K. and Dönmez, G. (2008). Environmental conditions affecting exopolysaccharide production by Pseudomonas aeruginosa, Micrococcus sp., and Ochrobactrum sp. . Journal of Hazardous Materials, 154, 1019-1024.

Zahoor, A., Rehman, A. (2009). Isolation of $\mathrm{Cr}$ (VI) reducing bacteria from industrial effluents and their potential use in bioremediation of chromium containing wastewater. Journal Environmental Science (China), 21, 814-820.

Polti, M.A., Amoroso, M.J. and Abate, C.M. (2010). Chromate reductase activity in Streptomyces sp. MC1. Journal Genetic Applied Microbiology, 56, 11-18.

Caravelli, A.H., Giannuzzi, L. and Zaritzky, N.E. (2008). Reduction of hexavalent chromium by Sphaerotilus natans a filamentous micro-organism present in activated sludges. Journal of Hazardous Materials, 156, 214-222. 